\title{
๖The Source of Uncertainty in Projecting the Anomalous Western North Pacific Anticyclone during El Niño-Decaying Summers
}

\author{
Mingna Wu, ${ }^{\mathrm{a}, \mathrm{b}}$ Tianjun Zhou, ${ }^{\mathrm{a}, \mathrm{b}, \mathrm{c}}$ AND XiaOlOng CHEN ${ }^{\mathrm{a}, \mathrm{c}}$ \\ ${ }^{\text {a } I n s t i t u t e ~ o f ~ A t m o s p h e r i c ~ P h y s i c s, ~ C h i n e s e ~ A c a d e m y ~ o f ~ S c i e n c e s, ~ B e i j i n g, ~ C h i n a ~}$ \\ ${ }^{\mathrm{b}}$ The University of Chinese Academy of Sciences, Beijing, China \\ ${ }^{\mathrm{c}}$ CAS Center for Excellence in Tibetan Plateau Earth Sciences, Chinese Academy of Sciences, Beijing, China
}

(Manuscript received 24 November 2020, in final form 14 May 2021)

\begin{abstract}
The western North Pacific anomalous anticyclone (WNPAC) is a key bridge that links El Niño and East Asian climate variability. Future projections of ENSO-related WNPAC changes under global warming are highly uncertain across climate models. Based on a 40-member ensemble from the Community Earth System Model Large Ensemble (CESM-LE) project, we investigate the effects of internal variability on the El Niño-related WNPAC projection. Here, we first develop a decomposition method to separate the contributions of El Niño amplitude change and nonamplitude change from the leading uncertainty in the El Niño-related WNPAC projection. Based on the decomposition, approximately $23 \%$ of the uncertainty in the El Niño-related WNPAC projection is attributed to the El Niño amplitude change, while the remaining $77 \%$ is from the nonamplitude change, which is mainly related to the change in the El Niño decaying pace. A larger (smaller) El Niño amplitude can enhance (weaken) the WNPAC through a stronger (weaker) tropical Indian Ocean capacitor effect. For nonamplitude change, a faster (slower) El Niño decaying pace can also enhance (weaken) the WNPAC through descending Rossby waves in response to cold sea surface temperature anomalies over the tropical central-eastern Pacific. The decomposition method can be generalized to investigate the sources of uncertainty related to El Niño properties in climate projections and to help improve the understanding of changes in the interannual variability of East Asian-western Pacific climate under global warming.
\end{abstract}

KEYWORDS: El Niño; Air-sea interaction; Climate models; Interannual variability

\section{Introduction}

The western North Pacific anomalous anticyclone (WNPAC) is a key atmospheric system that covers the impact of El NiñoSouthern Oscillation (ENSO) on East Asian climate variability (Chang et al. 2000; Wang et al. 2000; Wang et al. 2013; Li et al. 2017; Zhang et al. 2017). The WNPAC can regulate rainfall anomalies over East Asia, causing floods or droughts. For example, during the El Niño developing phase, the anomalous moisture transported by the WNPAC converges over southeastern China, whereas in the El Niño decaying phase the WNPAC brings a huge amount of water vapor into East Asia, which enhances precipitation along the mei-yu-baiu-changma front (Chang et al. 2000; Wang et al. 2000; Zhang et al. 2017). The WNPAC can also change the displacement and intensity of the western North Pacific subtropical high, impacting the genesis of tropical storm and typhoon tracks (Wang et al. 2013).

The WNPAC forms in the El Niño-developing autumn, develops in El Niño mature winter, and persists through the following spring and summer when El Niño decays. Great efforts have been devoted to investigating the mechanisms of formation and maintenance of the WNPAC. Both the remote forcing from the tropical central-eastern Pacific and local airsea interactions play roles in the formation of the WNPAC

¿ Denotes content that is immediately available upon publication as open access.

Corresponding author: Tianjun Zhou, zhoutj@lasg.iap.ac.cn during winter (Wang et al. 2000; Wang and Zhang 2002; Wang et al. 2003; Wu et al. 2017; Xie and Wang 2020). Maintenance of the summertime WNPAC is associated with different patterns of SSTA over tropical Indo-Pacific Ocean regions, including the tropical Indian Ocean (TIO) (Li et al. 2008; Xie et al. 2009; Wu et al. 2010a; He and Zhu 2015), western Pacific (Wu et al. 2010a), Maritime Continent (MC), and equatorial central Pacific (CP) (Wang et al. 2013; Xiang et al. 2013; Jiang et al. 2019; Zhou et al. 2019).

The observed ENSO-WNPAC relationship displays a significant decadal variation (Chang et al. 2000; Wu and Wang 2002; Chowdary et al. 2012). The strengthened relationship between ENSO and the western North Pacific (WNP) summer climate after the mid-1970s is due to enhanced ENSO activity (Wang et al. 2008) and enhanced ENSO-induced TIO warming (Huang et al. 2010; Xie et al. 2010). Moreover, the SSTA over the $\mathrm{CP}$ and the $\mathrm{MC}$ regions played a more important role than the TIO region on the interannual time scale after a decadal change in the 1990s (Chen and Zhou 2014; He and Zhou 2014). It is not entirely clear what causes these decadal changes in the ENSO-WNPAC teleconnection. Both global warming and internal decadal variability have been demonstrated to have an effect (Chowdary et al. 2012; Feng et al. 2013; Song and Zhou 2015), which adds complexity to the investigation of the future change in the ENSO-WNPAC relationship.

Understanding how the WNPAC, in response to ENSO, will change under global warming is of vital importance. Although at the interannual time scale the high predictability of the WNPAC allows monsoon and tropical storm predictions (Wang et al. 2013), the understanding of how ENSO-related 
WNPAC changes are associated with global warming remains inconclusive. Analyses based on the coupled atmosphereocean general circulation models from phase 5 of the Coupled Model Intercomparison Project (CMIP5) arrive at different conclusions. For example, it is argued that the El Niñoinduced TIO warming is enhanced by global warming, which will excite a warmer atmospheric Kelvin wave propagating into the WNP region, inducing stronger Ekman divergences to suppress the local convection, thus strengthening the WNPAC (Zheng et al. 2011; Hu et al. 2014). This process is called the enhanced TIO capacitor effect (Xie et al. 2009). On the contrary, recent studies propose that the El Niño-related WNPAC, in response to anthropogenic forcing, is projected to weaken, either due to changes in SSTA over the WNP region and weakened TIO-WNP SSTA gradients (Jiang et al. 2018) or due to the weakened latent heating anomaly over the TIO associated with the increased boundary layer static stability (He et al. 2019). There is a large intermodel spread in CMIP5 models when projecting the WNPAC (Wu et al. 2020). The ensemble-mean 50-yr running correlation coefficients between El Niño and the summertime WNPAC in 34 CMIP5 models show insignificant changes at the end of the twenty-first century compared to the second half of the twentieth century (Fig. 1a), with a large intermodel spread. The externally forced response represented by the multimodel ensemble mean is inconsistent with the observed El Niño-related WNPAC change, suggesting that anthropogenic forcing might be overwhelmed by internal variability. Therefore, whether the change in the El Niño-related WNPAC under global warming is dominated by internal variability or external anthropogenic forcing needs to be clarified.

Uncertainty in climate projections arises from three aspects: model response, scenario, and internal variability (Hawkins and Sutton 2009; Deser et al. 2010). It is difficult to disentangle internal variability and model error in the model spread of CMIP5 projections using the multimodel ensemble mean. Hence, the large ensemble of a single model is a helpful tool to separate the forced change and internal variability under the same scenario (Kay et al. 2015). The uncertainty in the forced response of the ENSO amplitude to global warming is large among different CMIP5 models (Zheng et al. 2016) and is mainly overwhelmed by internal variability based on the analysis of large ensembles (Zheng et al. 2017; Maher et al. 2018). Thus, the uncertainty of the projected WNPAC related to El Niño can be divided into two parts: the responses of El Niño amplitude and nonamplitude factors (such as the El Niño decaying pace and teleconnection) to global warming. There is extensive literature on the factors that affect the El Niño-related WNPAC, but little attention has been given to their relative contributions to the WNPAC projection. Our recent study found that uncertainty in projecting the El Niño decaying pace is a source of uncertainty in WNPAC projections in CMIP5 models (Wu et al. 2020), but whether this uncertainty comes from internal variability or the discrepancy of models' responses to external forcing remains unclear.

Here, we analyzed a 40-member large ensemble derived from the Community Earth System Model (CESM-LE) to investigate whether changes in the WNPAC during El Niño-decaying summers under global warming could be forced responses or due to internal variability. Our results show that internal variability is the dominant source of uncertainty in El Niñorelated WNPAC changes under global warming. The contributions of the El Niño amplitude change and the change of nonamplitude factors are separated and quantitatively estimated, and the relevant mechanisms are clarified.

The remaining parts of this paper are structured as follows. Section 2 introduces the data, models, and methods used throughout this study. Section 3 presents the simulated and projected El Niño-related WNPAC in CESM-LE. The contribution of different internal El Niño variabilities to the WNPAC projection uncertainty is provided in section 4. Finally, major conclusions and some discussions are presented in section 5 .

\section{Data and methods}

\section{a. Observational data}

The monthly mean atmospheric variables from the National Oceanic and Atmospheric Administration (NOAA) Twentieth Century Reanalysis (20CR) dataset (Compo et al. 2011) and the monthly mean SST from the Extended Reconstruction of Historical Sea Surface Temperature version 4 (ERSST4) dataset (Huang et al. 2016) are used to evaluate the performance of the model in simulating the ENSO-WNPAC relationship. Both observational data cover the time period from 1920 to 2014 .

\section{b. Model data}

The Community Earth System Model (CESM) large ensemble (CESM-LE) is designed to enable the assessment of climate change in the presence of internal variability. All the CESM-LE simulations share a single common CMIP5 coupled model: the Community Earth System Model version 1 with the Community Atmosphere Model version 5 [CESM1(CAM5)], which consists of coupled atmosphere, ocean, land, and sea ice component models (Hurrell et al. 2013). The horizontal resolution of CESM1(CAM5) is approximately $1^{\circ}$ in all the model components. All the CESM-LE members have the same external forcing following the CMIP5 design protocol, suggesting that the difference among them solely results from their initial atmospheric conditions; thus, internal variability is the only source of uncertainty in the CESM-LE projections. A 1800-yr dataset from the preindustrial control simulation of CESM-LE is also used to verify the influence of the internal variability. Additional information about the CESM-LE design can be found in Kay et al. (2015).

In addition to CESM-LE, the monthly outputs of 34 CMIP5 models are used to confirm the role of internal variability (more details can be found in Table 1). Only one realization (r1i1p1) for each model is analyzed to give equal weight and all the model data have been interpolated onto a $2.5^{\circ} \times 2.5^{\circ}$ grid before analysis. Another 50-member large ensemble from the Canadian Earth System Model version 2 (CanESM2) (KirchmeierYoung et al. 2017) is also used to verify the robustness of the results from the CESM-LE.

\section{c. Methods}

We focus on the future climate during 2050-99 in the representative concentration pathway 8.5 (RCP8.5) experiment 
with reference to 1951-2000 in the historical experiment. The Greek letter $\delta$ is used to represent the change in the El Niño-induced anomaly $X^{\prime}$ for simplicity, that is, $\delta X^{\prime}=$ $X_{\mathrm{RCP} 8.5}^{\prime}-X_{\text {Historical }}^{\prime}$. For all the variables, $X^{\prime}$ is calculated by regressing linearly onto the positive December (year 0)February (year 1) [D(0)JF(1)] Niño-3.4 index (defined as SST anomalies averaged over $5^{\circ} \mathrm{S}-5^{\circ} \mathrm{N}, 120^{\circ}-170^{\circ} \mathrm{W}$ ) for simplicity and to avoid the influence of La Niña events. Years 0 and 1 represent the previous and current years, respectively. To extract interannual variability, the linear trend, the annual cycle and 13-yr running mean are removed. The WNPAC index is defined as the area-averaged anomalous relative vorticity at $850 \mathrm{hPa}\left(\zeta_{850}\right)$ over the WNP region $\left(10^{\circ}-30^{\circ} \mathrm{N}, 110^{\circ}-160^{\circ} \mathrm{E}\right)$ multiplied by -1 (He and Zhou 2014). A larger WNPAC index indicates a stronger anticyclone in the WNP region.

To separate the impacts of external forcing and internal variability, we regard the multimember mean (MMM) of CESM-LE as the response to external forcing and the deviations of each ensemble member from the MMM as internal variability. Thus, for a certain variable $X^{\prime}$ related to El Niño, the separation in member $i$ can be expressed as

$$
X^{\prime}(i)=X_{\text {forced }}^{\prime}+X_{\text {internal }}^{\prime}(i), \quad i=1,2, \ldots, 39,40 .
$$

Here, we propose a decomposition method to separate the contribution of El Niño amplitude changes and other El Niño properties from the leading uncertainty in the WNPAC projection based on linear regression analysis. The $X^{\prime}$ related to the $\mathrm{D}(0)$ $\mathrm{JF}(1)$ standardized Niño-3.4 index (Niño3.4 $4_{\text {std }}$ ) is expressed as

$$
X^{\prime}=A \text { Niño3.4 }_{\text {std }}+\operatorname{Res}_{1},
$$

where the regression coefficients $A$ represent anomalies related to a normalized El Niño fluctuation with the same units as $X^{\prime}$ and $\mathrm{Res}_{1}$ is the residual. $X^{\prime}$ is directly regressed onto the $\mathrm{D}(0) \mathrm{JF}(1)$ original (unstandardized) Niño-3.4 index (Niño3.4) by the following equation:

$$
X^{\prime}=B \text { Niño3.4 }+\operatorname{Res}_{2},
$$

where the regression coefficients $B$ represent anomalies related to a full El Niño fluctuation with units of $X^{\prime}$ per $1 \mathrm{~K}$, as shown in the following equation:

$$
\text { Niño3.4 } 4_{\text {std }}=\frac{\text { Niño3.4 }}{\sigma}
$$

where $\sigma$ is the standard deviation of the $\mathrm{D}(0) \mathrm{JF}(1)$ Niño-3.4 index representing the El Niño amplitude. Combining Eqs. (2)-(4) yields

$$
A=\sigma B+\frac{e_{2}-e_{1}}{\text { Niño3.4 }} .
$$

Ignoring the higher-order residual terms $\operatorname{Res}_{1}$ and $\mathrm{Res}_{2}$, Eq. (5) becomes

$$
A \approx \sigma B \text {. }
$$

Hence, the El Niño-related WNPAC (A) is determined according to the amplitude of $\mathrm{El}$ Niño $(\sigma)$ and the contributions from nonamplitude factors $(B)$.
For each member from CESM-LE, changes of the regression coefficients $A$ between the future and present climate can be computed from

$$
\delta A \approx \delta(\sigma B),
$$

containing the information of the changes in El Niño amplitude. Equation (7) can be expanded linearly by

$$
\delta A \approx \delta(\sigma B) \approx \sigma_{H} \delta B+\delta \sigma B_{H}+\text { Res },
$$

where $B_{\mathrm{H}}$ is the regression coefficient regressed onto the original Niño-3.4 index in the historical experiment, $\sigma_{H}$ is the historical amplitude of $\mathrm{El} \mathrm{Niño,} \mathrm{and} \mathrm{Res} \mathrm{is} \mathrm{the} \mathrm{residual}$ nonlinear term.

Based on a large ensemble, uncertainty across individual members can be obtained by computing the empirical orthogonal function over the ensemble dimension (EOF-E). We apply EOF-E to $\delta A$ over the WNP region to capture the leading mode of uncertainty in the El Niño-related WNPAC change under global warming. Regardless of other higherorder EOF modes (EOF2, EOF3, etc.), term $\delta A$ can be expressed as

$$
\delta A=k \mathrm{PC} 1+\delta A^{\prime}+\overline{\delta A},
$$

where $k$ is the leading mode of uncertainty (i.e., EOF1), PC1 is the leading principal component, $\delta A^{\prime}$ represents the PC1unrelated part, and $\overline{\delta A}$ is the intercept term obtained from the multimember ensemble mean.

Similarly, the terms $\delta \sigma, \delta B, B_{H}$, and $\sigma_{H}$ relating to the leading mode of uncertainty can be expressed as

$$
\begin{gathered}
\sigma_{H}=k_{1} \mathrm{PC} 1+\sigma_{H}^{\prime}+\overline{\sigma_{H}}, B_{H}=k_{2} \mathrm{PC} 1+B_{H}^{\prime}+\overline{B_{H}}, \\
\delta \sigma=k_{3} \mathrm{PC} 1+\delta \sigma^{\prime}+\overline{\delta \sigma}, \delta B=k_{4} \mathrm{PC} 1+\delta B^{\prime}+\overline{\delta B},
\end{gathered}
$$

where $k_{1}, k_{2}, k_{3}$, and $k_{4}$ are the regression coefficients onto $\mathrm{PC} 1$, and $\overline{\delta \sigma}, \overline{\delta B}, \overline{\sigma_{H}}$ and $\overline{B_{H}}$ are the intercept terms obtained from the multimember ensemble means, representing externally forced signals. The terms $\sigma_{H}^{\prime}, B_{H}^{\prime}, \delta \sigma^{\prime}$, and $\delta B^{\prime}$ are the PC1-unrelated parts in corresponding terms. Thus, for the first two right-hand terms in Eq. (8),

$$
\begin{aligned}
\sigma_{H} \delta B & =\left(k_{1} \mathrm{PC} 1+\sigma_{H}^{\prime}+\overline{\sigma_{H}}\right) \cdot\left(k_{4} \mathrm{PC} 1+\delta B^{\prime}+\overline{\delta B}\right) \\
& \approx\left(\overline{\delta B} k_{1}+\overline{\sigma_{H}} k_{4}\right) \mathrm{PC} 1+\overline{\sigma_{H}} \overline{\delta B}, \\
\delta \sigma B_{H} & =\left(k_{3} \mathrm{PC} 1+\delta \sigma^{\prime}+\overline{\delta \sigma}\right) \cdot\left(k_{2} \mathrm{PC} 1+B_{H}^{\prime}+\overline{B_{H}}\right) \\
& \approx\left(\overline{B_{H}} k_{3}+\overline{\delta \sigma} k_{2}\right) \mathrm{PC} 1+\overline{\delta \sigma} \overline{B_{H}} .
\end{aligned}
$$

In Eq. (12), higher-order terms $\left(\mathrm{PC}^{2}\right)$ are omitted. Since we mainly focus on the PC1-related variability, terms reflecting the influence of PC1-unrelated variability (terms that contain $\sigma_{H}^{\prime}, B_{H}^{\prime}, \delta \sigma^{\prime}$, and $\delta B^{\prime}$ ) are also omitted. Combining Eqs. (8), (9), and (12) yields

$$
k \approx \overline{\delta B} k_{1}+\overline{\delta \sigma} k_{2}+\overline{B_{H}} k_{3}+\overline{\sigma_{H}} k_{4} .
$$

In Eq. (13), the leading uncertainty in the WNPAC projection related to El Niño $(k)$ can be decomposed into four parts, from left to right on the right-hand side: 1) historical amplitude 


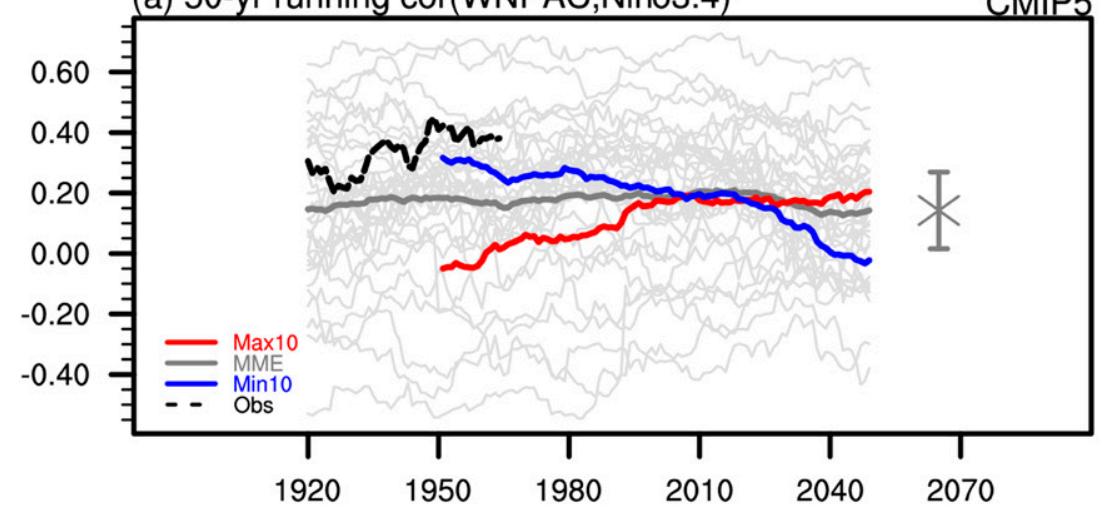

(b) 50-yr running cor(WNPAC,Niño3.4)

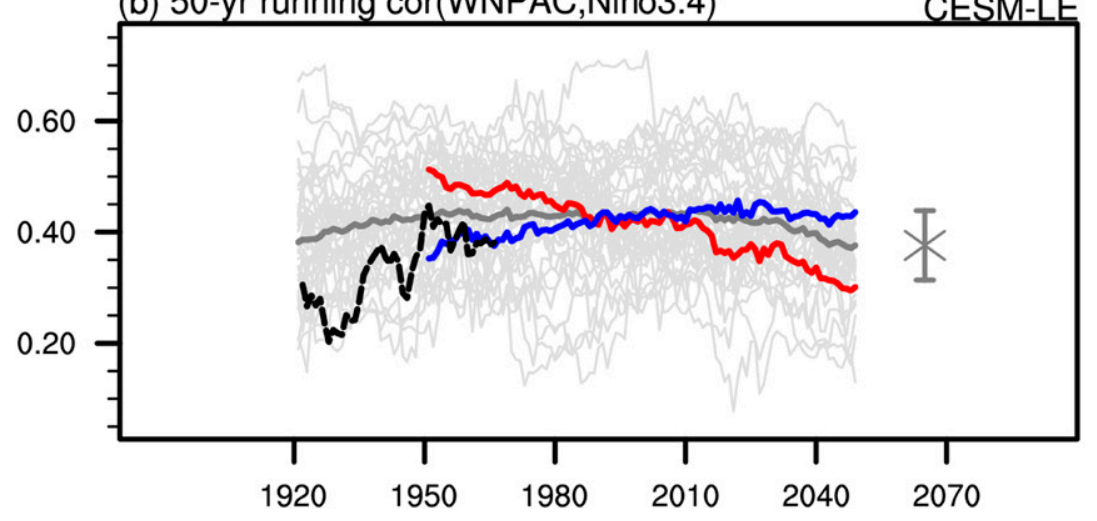

(c) $\operatorname{Max} 10$

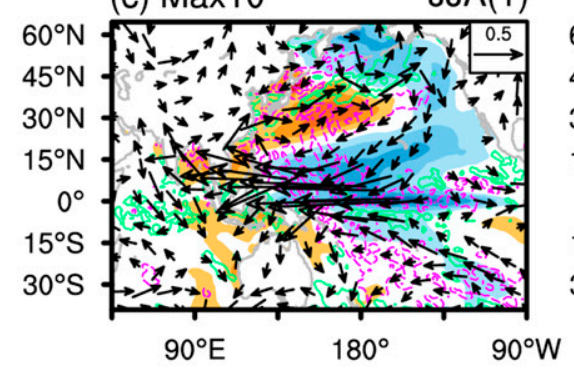

(d) Min10

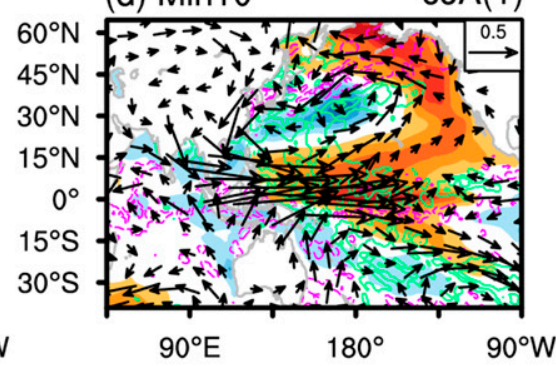

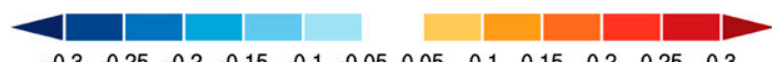

FIG. 1. 50-yr running correlation coefficients between the JJA(1) WNPAC index and the D(0)JF(1) Niño-3.4 index for the time period of 1920-2099 in (a) CMIP5 and (b) CESM-LE. The black dashed line is based on the 1920-2014 period of observational data, and the gray thick line denotes the multimember ensemble mean. The red and blue lines denote the 10 ensemble members with the most increased and decreased El Niño-WNPAC variability in 2050-99 compared to 1951-2000, respectively. The error bar is the standard deviation of the intermodel (intermember) spread in the difference between these two periods. (c) Spatial distribution of changes in El Niño-related SST (shading; units: $\mathrm{K}^{-1}$ ), precipitation (contours; units: $\mathrm{mm} \mathrm{day}^{-1}$ ), and 850-hPa wind (vectors; units: $\mathrm{m} \mathrm{s}^{-1}$ ) anomalies over the western North Pacific in 2050-99 compared to 1951-2000 for 10 ensemble members showing the largest strengthening (Max10) and (d) weakening (Min10). The El Niño-related SST, precipitation, and wind anomalies are obtained by regressing variables onto the standardized Niño-3.4 index. The green (purple) lines represent the positive (negative) precipitation anomalies. The contours range from -0.40 to $0.40 \mathrm{~mm} \mathrm{day}^{-1}$ with an interval of $0.15 \mathrm{~mm} \mathrm{day}^{-1}$. 
uncertainty $\left(k_{1}\right)$-uncertainty in El Niño amplitude across members in the historical experiment; 2 ) historical nonamplitude uncertainty $\left(k_{2}\right)$-uncertainty from the response of the WNPAC to El Niño across members in the historical experiment; 3) amplitude change uncertainty $\left(k_{3}\right)$ - uncertainty from El Niño amplitude changes; and 4) nonamplitude change uncertainty $\left(k_{4}\right)$-uncertainty from future changes in the response of the WNPAC to an El Niño with the same amplitude as in historical period. It is noted that external forcing (i.e., multimember ensemble mean of all members in a single model) has an effect on the leading uncertainty related to internal variability (i.e., intermember spread among individual members), indicating interactions between external forcing and internal variability.

Historical amplitude uncertainty and amplitude change uncertainty are considered as uncertainties in El Niño amplitude, while historical nonamplitude uncertainty and nonamplitude change uncertainty are taken as uncertainties in nonamplitude factors, including changes in other aspects of El Niño, such as El Niño decaying pace. Equation (13) also indicates that both the uncertainty in the historical simulation and future response can contribute to the leading uncertainty in the projection. The sum of the four decomposed terms is regarded as the total approximate uncertainty. To measure the accuracy of the decomposition method, we calculate pattern correlation between the leading uncertainty and the total approximate uncertainty. The residual term, which is the difference between the left and right terms, is also evaluated.

\section{EI Niño-WNPAC relationship change in CESM-LE}

\section{a. Model evaluation}

The performance of CESM-LE in simulating the El NiñoWNPAC relationship is first evaluated by showing the seasonal evolution of the correlation coefficients between the WNPAC index and the $\mathrm{D}(0) \mathrm{JF}(1)$ Niño-3.4 index (Fig. 2). CESM-LE performs well in simulating the El Niño-WNPAC relationship. The observed WNPAC in boreal summer is associated with the El Niño decaying phase from the previous autumn (Fig. 2b). The WNPAC starts to develop in winter, maintains into the following spring, and fully establishes in summer. We then examine the spatial evolution of the El Niño-related WNPAC in observation and the multimember ensemble mean of CESM-LE (Figs. 2bg). Although the WNPAC in CESM-LE develops much faster than that observed in the previous winter (Fig. 2a), CESM-LE adequately reproduces the seasonal features of the WNPAC associated with the El Niño evolution with a small uncertainty covering the observational fluctuation, especially from late winter to summer (Figs. 2b-g). In contrast to most CMIP5 models that cannot capture the El Niño-WNPAC teleconnection (Jiang et al. 2017), CESM-LE can reasonably capture the characteristics of the WNPAC seasonal evolution, which adds confidence to our following analysis of the WNPAC projection.

\section{b. External and internal variability of the El Niño-WNPAC relationship}

To examine the relative roles of external forcing and internal variability, we calculated the 50-yr running correlation between
El Niño and the summertime WNPAC during the 19202099 period in CESM-LE (Fig. 1b). The externally forced result, represented by the ensemble mean, shows no significant trend since the early twentieth century (1920-69), although it slightly decreases from 0.43 during 1951-2000 to 0.38 during 2050-99 (Fig. 1b, gray thick line). The relationship change is even less compared to that in the early twentieth century $(-0.006)$. It is evident that the uncertainty caused by internal variability is large. The El Niño-WNPAC relationship in the 20CR reanalysis shows an enhancement with increasing trend of $0.18(45 \mathrm{yr})^{-1}$ during the twentieth century with large decadal fluctuations, which are, however, within the range of the internal variability $\left[-0.23-0.34(45 \mathrm{yr})^{-1}\right]$ in CESM-LE. In contrast to the small impact of external forcing, internal variability has a much larger impact on future changes in the El Niño-WNPAC relationship, dominating the large intermember spread in the changes in the correlation coefficients between 2050-99 and 1951-2000, which range from -0.44 to 0.25 (Fig. 1b, gray thin lines). Compared with CESM-LE, there also exists large intermodel spread in changes in the 50yr running correlation coefficients during the same periods in CMIP5 models, with a wider range of -0.47 to 0.48 (Fig. 1a). Given that different CMIP models may have may include different implementation of the forcings and differ in dynamical cores and physical package, uncertainties generated by internal variability may be confounded with model error based on CMIP5 models.

To further confirm the role of internal variability, we examined the associated climate changes over the WNP region. The change in spatial distributions of SST and atmospheric circulation anomalies related to El Niño for 10 members showing the largest strengthening (hereafter referred to as Max10) and weakening (hereafter referred to as Min10) are shown in Figs. 1c and 1d, respectively. With different WNPAC changes, the anomalous circulations show opposite patterns associated with contrasting SST anomalies over the WNP (Figs. 1c,d). For Max10, convection is suppressed, as indicated by the negative precipitation anomalies, leading to an anomalous anticyclone over the WNP region. The anomalous lowlevel easterlies over the tropical western Pacific and the MC are also evident (Fig. 1c). By contrast, warmer SST anomalies are seen in Min10 over large areas from the northern region of WNP to the western equatorial Pacific $\left(0^{\circ}-15^{\circ} \mathrm{N}, 120^{\circ}-160^{\circ} \mathrm{E}\right)$, resulting in a weakened atmospheric circulation (Fig. 1d), which further implies that internal variability can regulate the change in WNPAC, thus causing different climate effects.

\section{Roles of internal El Niño variabilities in WNPAC projection}

The intensity of the WNPAC is substantially modulated by El Niño. When El Niño properties (such as amplitude) change due to global warming, the WNPAC is expected to change as well. Therefore, the uncertainty in the WNPAC projection is associated with the El Niño projection to a large extent and may arise from two aspects. The first aspect is the uncertainty in the amplitude change of El Niño. If the El Niño amplitude is enhanced, then a stronger WNPAC is expected, and vice versa. 
TABLE 1. Information for the 34 CMIP5 models used in this study.

\begin{tabular}{|c|c|}
\hline Model name & Institute \\
\hline $\begin{array}{l}\text { ACCESS1.0 } \\
\text { ACCESS1.3 }\end{array}$ & $\begin{array}{l}\text { Commonwealth Scientific and Industrial Research Organisation and Bureau of Meteorology } \\
\text { (CSIRO-BOM) }\end{array}$ \\
\hline BCC-CSM1.1 & Beijing Climate Centre, China Meteorological Administration (BCC) \\
\hline \multicolumn{2}{|r|}{ (2) } \\
\hline BNU-ESM & College of Global Change and Earth System Science, Beijing Normal University (GCESS) \\
\hline CanESM2 & Canadian Centre for Climate Modelling and Analysis (CCCMA) \\
\hline CCSM4 & National Center for Atmospheric Research (NCAR) \\
\hline \multicolumn{2}{|l|}{ CESM1(BGC) } \\
\hline \multicolumn{2}{|l|}{ CESM1(CAM5) } \\
\hline CMCC-CM & Centro Euro-Mediterraneo per I Cambiamenti Climatici (CMCC) \\
\hline CNRM-CM5 & $\begin{array}{l}\text { Centre National de Recherches Météorologiques/Centre Européen de Recherche et Formation Avancée } \\
\text { en Calcul Scientifique (CNRM-CERFACS) }\end{array}$ \\
\hline CSIRO-Mk3.6.0 & $\begin{array}{l}\text { Commonwealth Scientific and Industrial Research Organisation in collaboration with Queensland } \\
\text { Climate Change Centre of Excellence (CSIRO-QCCCE) }\end{array}$ \\
\hline FGOALS-g2 & LASG, Institute of Atmospheric Physics, Chinese Academy of Sciences (LASG-IAP) \\
\hline \multicolumn{2}{|r|}{ 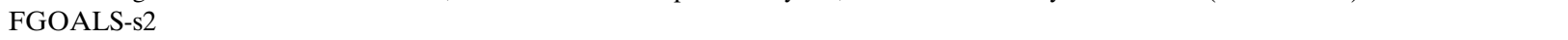 } \\
\hline GFDL CM3 & NOAA Geophysical Fluid Dynamics Laboratory (NOAA GFDL) \\
\hline \multicolumn{2}{|l|}{ GFDL-ESM2G } \\
\hline \multicolumn{2}{|l|}{ GFDL-ESM2M } \\
\hline GISS-E2-H & NASA Goddard Institute for Space Studies (NASA GISS) \\
\hline \multicolumn{2}{|r|}{ 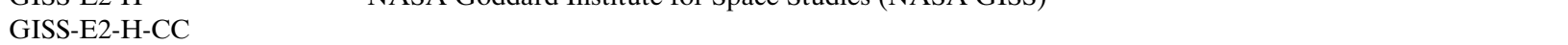 } \\
\hline \multicolumn{2}{|l|}{ GISS-E2-R } \\
\hline \multicolumn{2}{|l|}{ GISS-E2-R-CC } \\
\hline HadGEM2-AO & Met Office Hadley Centre (additional HadGEM2-ES realizations contributed by Instituto Nacional de \\
\hline HadGEM2-ES & Pesquisas Espaciais) (MOHC additional realizations by INPE) \\
\hline INM-CM4 & Institute for Numerical Mathematics (INM) \\
\hline IPSL-CM5A-LR & Institut Pierre-Simon Laplace (IPSL) \\
\hline \multicolumn{2}{|l|}{ IPSL-CM5B-LR } \\
\hline MIROC5 & $\begin{array}{l}\text { Atmosphere and Ocean Research Institute (The University of Tokyo), National Institute for } \\
\text { Environmental Studies, and Japan Agency for Marine-Earth Science and Technology }\end{array}$ \\
\hline MIROC-ESM & Japan Agency for Marine-Earth Science and Technology, Atmosphere and Ocean Research Institute \\
\hline MIROC-ESM-CHEM & (The University of Tokyo), and National Institute for Environmental Studies \\
\hline MPI-ESM-LR & Max-Planck-Institut für Meteorologie (Max Planck Institute for Meteorology) (MPI-M) \\
\hline \multicolumn{2}{|r|}{ ( } \\
\hline MRI-CGCM3 & Meteorological Research Institute (MRI) \\
\hline NorESM1-M & Norwegian Climate Centre (NCC) \\
\hline NorESM1-ME & \\
\hline
\end{tabular}

The second aspect is the change in nonamplitude factors, such as El Niño decaying pace and internal atmospheric variability. Under a warmer climate, it may be possible for the amplitude of El Niño itself to remain unchanged, while other internal El Niño properties change, leading to a strengthened or weakened El Niño-driven teleconnection. Moreover, it is possible that the internal atmospheric variability can modulate the El Niño-related teleconnection without any change of El Niño properties (Deser et al. 2018).

\section{a. Decomposition of the uncertainty in WNPAC changes}

Here, we use the uncertainty decomposition method [see section 2c, Eq. (13)] to separate the contributions of El Niño amplitude changes and nonamplitude changes from the leading uncertainty in the WNPAC projection. We regress the anomalous relative vorticity at $850 \mathrm{hPa}\left(\zeta_{850}\right)$ onto the standardized Niño-3.4 index to represent the El Niño-related WNPAC. Thus, the leading uncertainty in the WNPAC projection is calculated by applying EOF-E to changes in the
El Niño-related $\zeta_{850}\left(\delta \zeta_{850}\right)$ in JJA(1) over the WNP region. The first EOF mode (EOF1) explains $33.9 \%$ of the total variance, displaying a spatial distribution with a meridional dipole pattern over the WNP and equatorial western Pacific regions (Fig. 3a). The intermember correlation coefficient between the changes in the WNPAC index and the PC1 is 0.92 , suggesting that EOF1 appropriately represents the changes in WNPAC strength (Fig. 3c). Members with negative PC1s indicate a weaker WNPAC during an El Niño decaying summer in a warmer future, whereas positive PC1s indicate a stronger WNPAC.

To further understand the roles of the changes in El Niño amplitude and nonamplitude factors based on Eq. (13) (see section 2c), the leading uncertainty and the four contribution terms are shown in Fig. 4. To evaluate the accuracy of the decomposition method, the sum of the four terms (Fig. 4b), referred to as "total approximate uncertainty," is compared with the original leading uncertainty (Fig. 4a). This result shows that the method can reasonably describe the main 
(a)Evolution of cor(WNPAC,Niño3.4)

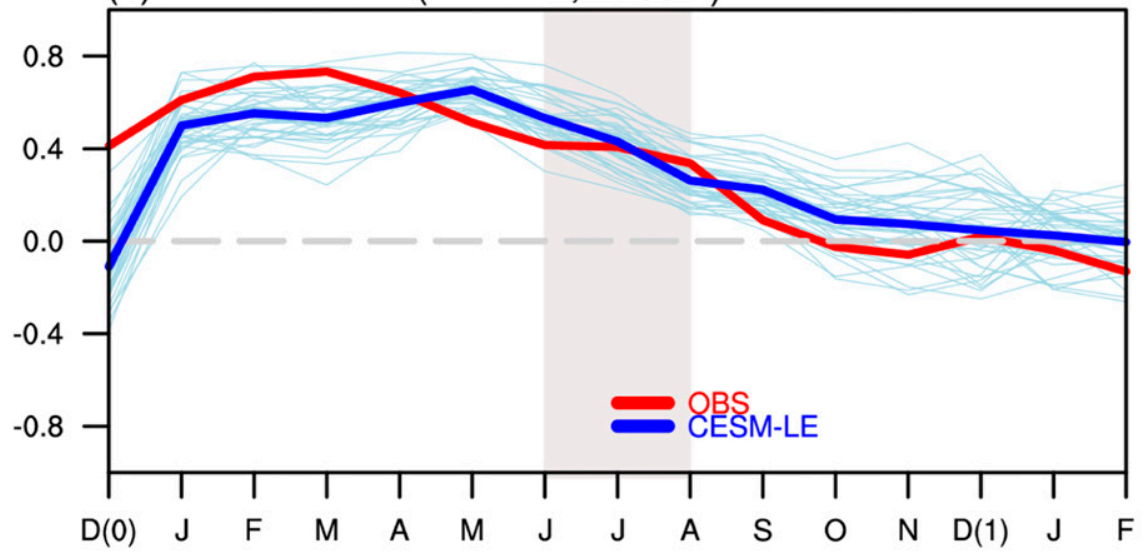

(b)Observation $\mathrm{D}(0) \mathrm{JF}(1)$
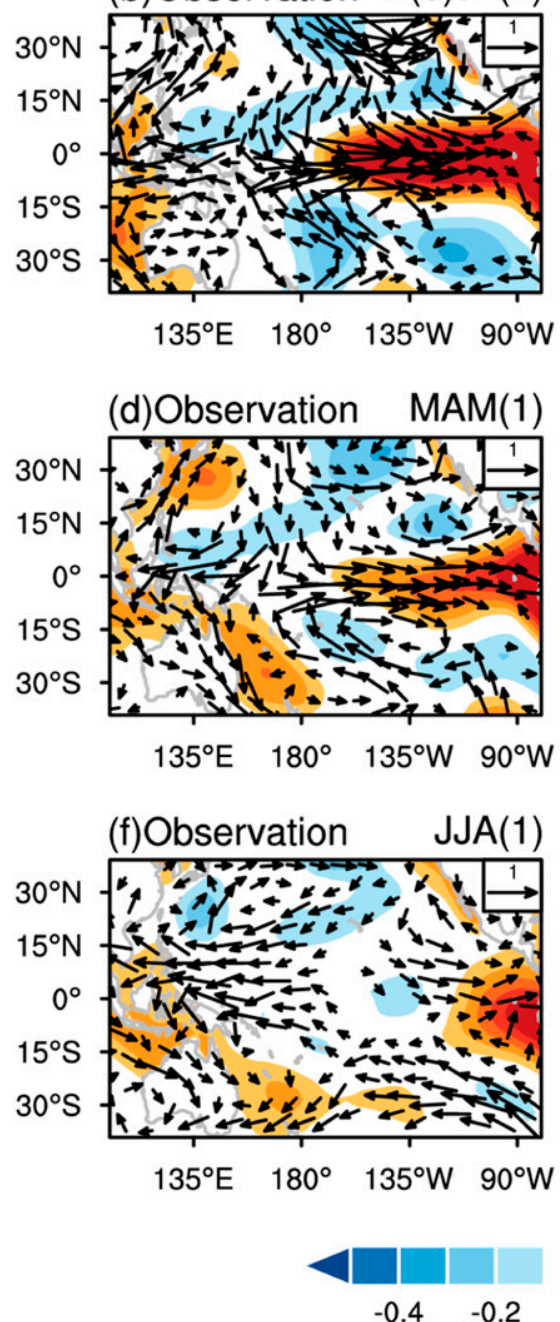

(c)CESM-LE $\quad \mathrm{D}(0) \mathrm{JF}(1)$

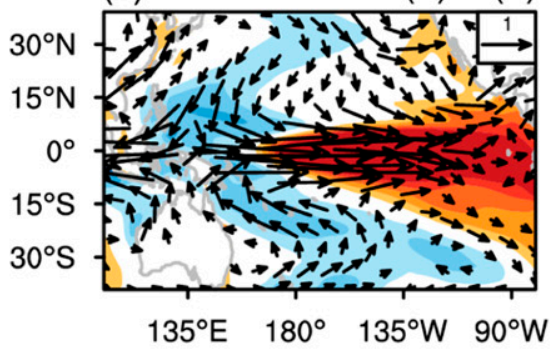

(e)CESM-LE MAM(1)

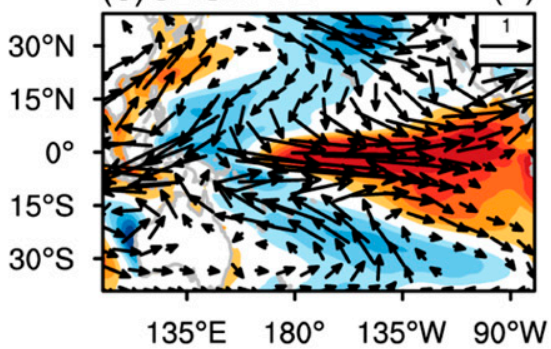

(g)CESM-LE JJA(1)
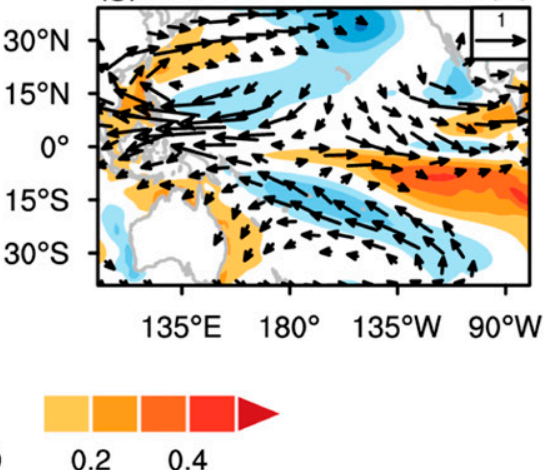

FIG. 2. (a) Evolution of the correlation coefficients between the WNPAC index and the D $(0)$ JF(1) Niño-3.4 index in the observation (red line) and CESM-LE (blue thick line) during 1951-2000. The blue thin lines indicate individual members from CESM-LE. The shading indicates the following summer [JJA(1)] of El Niño events. (b)-(g) Spatial evolution of El Niño-related SST (shading; units: $\mathrm{K}^{-1}$ ) and 850-hPa wind (vectors; units: $\mathrm{m} \mathrm{s}^{-1}$ ) anomalies from $\mathrm{D}(0) \mathrm{JF}(1)$ to JJA(1) in (left) observations and (b) the multimember ensemble mean for CESM-LE. The El Niño-related SST and wind anomalies are obtained by regressing variables onto the standardized Niño-3.4 index. 
(a)EOF1

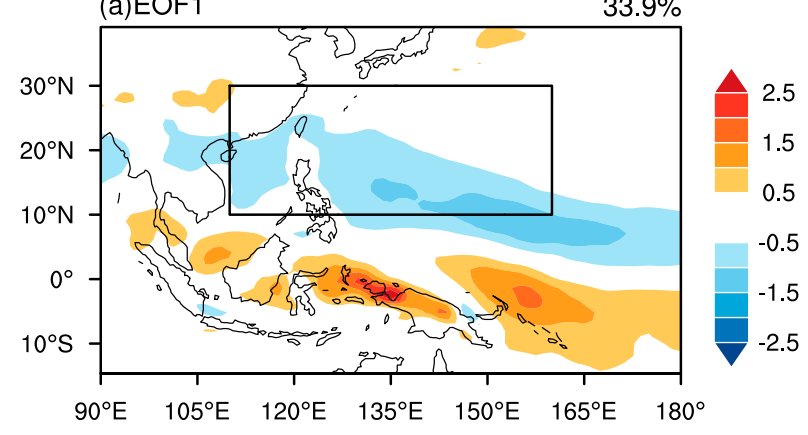

(b)PC1

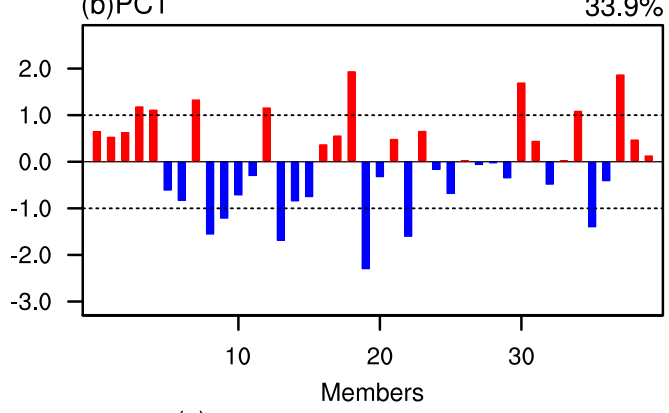

(c)

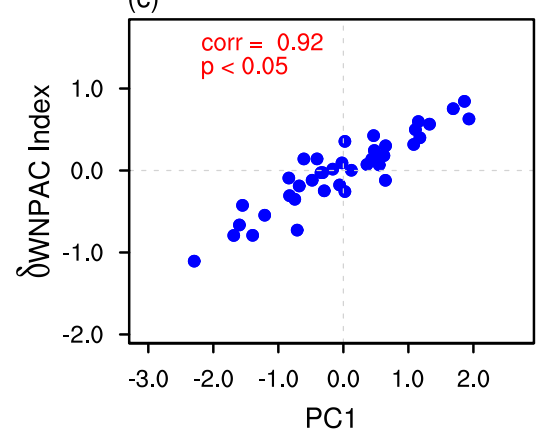

FIG. 3. (a) The first intermember EOF patterns of $\delta \zeta_{850}$ (shading; units: $10^{-6} \mathrm{~s}^{-1} \mathrm{~K}^{-1}$ ) with explained variance noted in the top right. The box denotes the WNP region $\left(10^{\circ}-30^{\circ} \mathrm{N}, 110^{\circ}-160^{\circ} \mathrm{E}\right)$ to do EOF-E analysis. (b) Standardized PC1 of intermodel EOF1. (c) The $\delta$ WNPAC index in JJA(1) ( $y$ axis) as a function of PC1 ( $x$ axis). The correlation coefficient is 0.92 and is significant at the $95 \%$ confidence level through the Student's $t$ test.

sources of uncertainty in $\delta \zeta_{850}$, with a spatial pattern correlation coefficient of 0.98 (Fig. $4 \mathrm{~b}$ ). Moreover, the intermember correlation coefficient between changes in the original WNPAC index and changes in the approximate WNPAC index calculated from Eqs. (9) and (13) for all 40 members is 0.92 (figure not shown), confirming the reasonableness of the approximation. The decomposition results suggest that the uncertainty of WNPAC changes is mainly from the nonamplitude change uncertainty (Fig. 4f), which reflects changes in WNP circulation in response to El Niño-related SST anomalies without changes in El Niño amplitude.

Quantitatively, for the area-averaged uncertainty over the WNP region (Fig. 5), approximately $77 \%$ of the WNPAC change uncertainty stems from the nonamplitude change uncertainty, while $23 \%$ arises from the amplitude change uncertainty of El Niño. Both the historical amplitude uncertainty and historical nonamplitude uncertainty contribute little to the leading uncertainty and thus can be neglected. This is because in these two terms, the multimember means of the change in $\mathrm{El}$ Niño amplitude $(\overline{\delta \sigma})$ and the change in the WNPAC in response to an SST anomaly $(\overline{\delta B})$ are very small, indicating that external forcing makes a small contribution to the uncertainty in WNPAC projection. The total approximate uncertainty slightly overestimates the original uncertainty with less than $5.0 \%$ bias (Fig. 5) and confirms the validity of the decomposition. The above results indicate that nonamplitude change uncertainty and amplitude change uncertainty are the two main sources for the WNPAC projection uncertainty, whereas historical nonamplitude uncertainty and historical amplitude uncertainty can be neglected.

\section{b. Roles of internally driven El Niño variabilities}

To address how the amplitude change uncertainty affects the WNPAC projection and what processes are responsible for the nonamplitude change uncertainty, we apply the decomposition method to the spatial changes in El Niño-related SST, precipitation, and low-level wind anomalies (Fig. 6). The total approximate uncertainty appropriately captures the seasonal evolution characteristics of the uncertainty in the WNPAC change. From winter to the following spring, changes in warm SST anomalies with low-level westerlies and positive precipitation anomalies over the tropical eastern Pacific are the most evident uncertainty signals among the different members, directly indicating the role of amplitude change uncertainty (Figs. 6a-d).

Although El Niño amplitude is the most direct factor that modulates the El Niño-WNPAC relationship, the importance of the El Niño decaying pace has recently received more attention (Jiang et al. 2019; Zhou et al. 2019; Wu et al. 2020). A fast decaying El Niño leads to a significant WNPAC, whereas a slow decaying El Niño is associated with a disappeared or weakened western-part WNPAC due to the different patterns of the simultaneous tropical SSTA (Chen et al. 2012; Chen et al. 2016; Jiang et al. 2019; Zhou et al. 2019). During summer, the changes in the cooling of the tropical central Pacific (TCP) and equatorial easterlies also show large uncertainty (Figs. 6e,f). TCP cooling can suppress convection and cause descending Rossby waves to occur westward to strengthen the WNPAC (Wang et al. 2013; Xiang et al. 2013). Meanwhile, equatorial easterlies can accelerate the demise of El Niño in turn, which is helpful for tropical central-eastern Pacific cooling (Wu et al. 2020). Thus, the nonamplitude change uncertainty could be determined according to the uncertainty of the El Niño decaying pace along with TCP cooling.

Decomposition analysis of the spatial distributions indicate that the two major sources of uncertainty in the WNPAC projection are from changes in SST anomalies of El Niño during winter and the El Niño decaying pace during summer. To further test the above hypotheses, we compared changes in the El Niño amplitude and PC1 of the intermember EOF1 for individual members (Fig. 7a). The intermember correlation coefficient is 0.58 , suggesting that an enhanced El Niño 


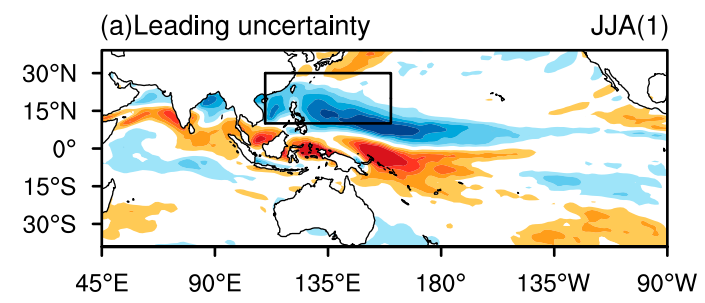

(c) Historical amplitude uncertainty

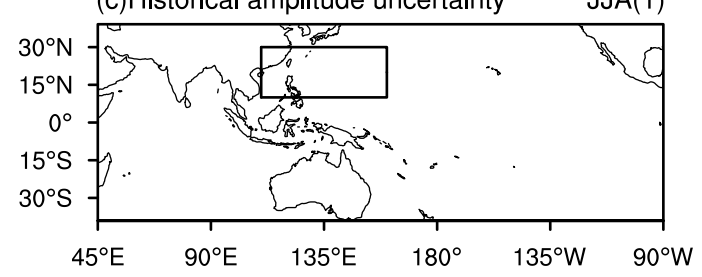

(e)Amplitude change uncertainty

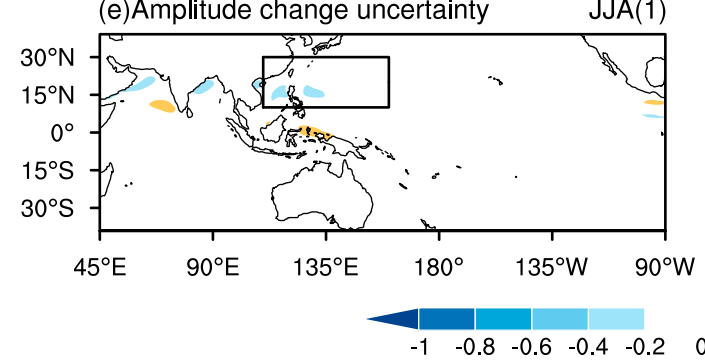

(b)Total approximate uncertainty

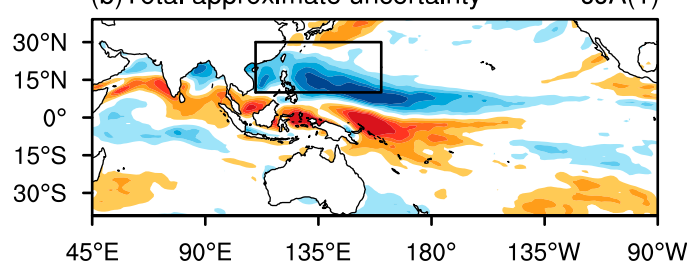

(d)Historical non-amplitude uncertainty $\mathrm{JJA}(1)$

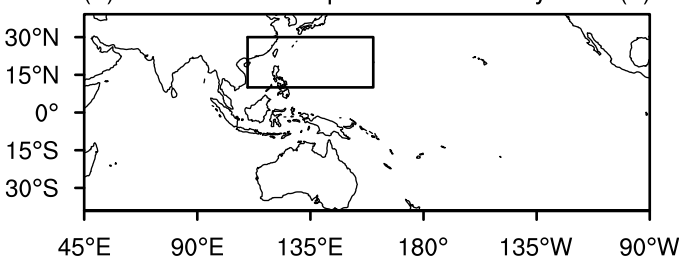

(f)Non-amplitude change uncertainty

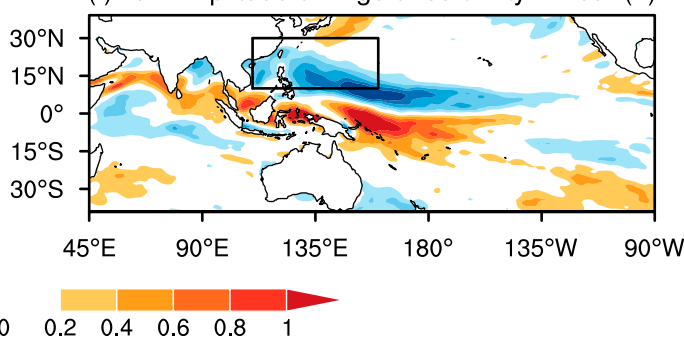

FIG. 4. Decomposition of $\delta \zeta_{850}$ in JJA(1) (units: $10^{-6} \mathrm{~s}^{-1}$ ) for (a) leading uncertainty, (b) total approximate uncertainty, (c) historical amplitude uncertainty, (d) historical nonamplitude uncertainty, (e) amplitude change uncertainty, and (f) nonamplitude change uncertainty. The box denotes the WNP region.

amplitude corresponds to a stronger WNPAC. Since the El Niño decaying pace may contribute to the response uncertainty, we define an El Niño decaying pace index as the positive JJA(1) Niño-3.4 index minus the positive D(0)JF(1) Niño-3.4 index to examine whether the decaying index can explain the remaining uncertainty in the $\mathrm{PC}$ after the impact of the El Niño amplitude change is removed. $\mathrm{PC}^{\prime}$ is obtained by removing the linear correlation between PC1 and the El Niño amplitude change from PC1. The intermember correlation coefficient between $\mathrm{PC1}^{\prime}$ and the El Niño decaying pace change is -0.35 , suggesting that a faster El Niño decay (more negative) corresponds to a stronger WNPAC (Fig. 7b).

To ensure that the above relationships are robust in pure internal variability and without greenhouse gas forcing, we examine the influences of these two El Niño properties based on the 1800-yr CESM1 preindustrial control run (Figs. 7c,d). We compute the differences in the El Niño amplitude, El Niño decaying pace, and WNPAC index between the last and first 50 years in a 145-yr segment selected at intervals of 20 years from the unforced control run (in total 82 samples). The intermember correlation coefficient between the WNPAC index and the El Niño amplitude change is 0.29 , confirming the positive role of the El Niño amplitude in modulating the El Niño-WNPAC relationship. After removing the linear influence of the El Niño amplitude change, the correlation coefficient between the WNPAC index' and the El Niño decaying pace change is -0.27 , validating the negative role of the El Niño decaying pace. Note that El Niño decaying pace change can only explain a restricted part of the nonamplitude change uncertainty (Figs. 7b,d), which suggests the role of other factors such as the internal atmospheric variability.

In summary, the spatial changes in SST and atmospheric circulation anomalies manifest the roles of changes in the wintertime El Niño-induced warm SST anomalies in the tropical eastern Pacific and the summertime TCP cooling determined by the El Niño decaying pace. The correlation analysis further confirms that both the El Niño amplitude and El Niño decaying pace are important as internal variabilities.

\section{c. Mechanisms underlying different sources of WNPAC uncertainty}

To illustrate the underlying mechanisms of the El Niñorelated internal variabilities that affect the WNPAC change, the spatial distributions of the amplitude and nonamplitude change uncertainties, based on decomposition analysis, are shown in Fig. 8. For the amplitude change uncertainty, El Niño amplitude changes mainly influence the uncertainty in the WNPAC projection via the TIO capacitor effect. The members that project enhanced (weakened) SST variance have significantly increased (decreased) warm SST anomalies over the equatorial eastern Pacific in winter, along with strengthened (weakened) anomalous westerlies and positive precipitation 


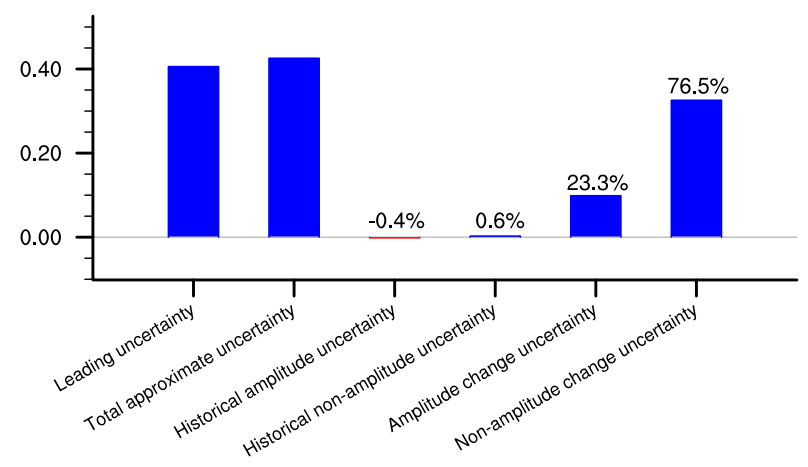

FIG. 5. Area-averaged uncertainty in $\delta \zeta_{850}$ in JJA(1) (units: $10^{-6} \mathrm{~s}^{-1}$ ) over the WNP region based on the decomposition equation. The relative ratios of the four decomposition terms to the total approximate uncertainty are labeled above each bar.

anomalies. From winter to the following spring, both the enhanced (weakened) atmospheric circulation and the dipolelike SST pattern change over the Indian Ocean region indicate that the TIO capacitor effect is enhanced (weakened) (Figs. 8a,c,e).
This enhanced (weakened) TIO capacitor effect then strengthens (weakens) the WNPAC by producing strengthened (weakened) northwestward-propagating warm Kelvin waves. Moreover, since the cold SSTA over the WNP region during the El Niño mature phase can also modulate the WNPAC by suppressing local precipitation (Wu et al. 2010a), the uncertainty in the SST of the WNP persisting through the subsequent spring and summer may also contribute to the WNPAC change uncertainty (Figs. 8a,c,e).

For the nonamplitude change uncertainty, changes in the El Niño decaying pace are modulated by midlatitude processes. Previous studies have suggested that the North Pacific Oscillation (NPO), the second leading internal atmospheric mode over the North Pacific (Park et al. 2012; Chen and $\mathrm{Yu}$ 2020), could exert significant influence on ENSO during the following seasons via the seasonal footprinting mechanism (SFM) (Vimont et al. 2001; Vimont et al. 2003b). Specifically, when high pressure occupies the southern lobe of the NPO in winter (figures not shown), centered at approximately $35^{\circ}$, anticyclonic wind anomalies appear over the northeastern subtropical Pacific (Fig. 8b). The northeasterly
(a)Leading uncertainty

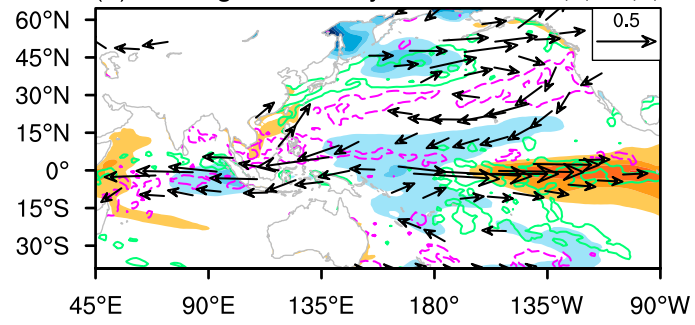

(c)Leading uncertainty

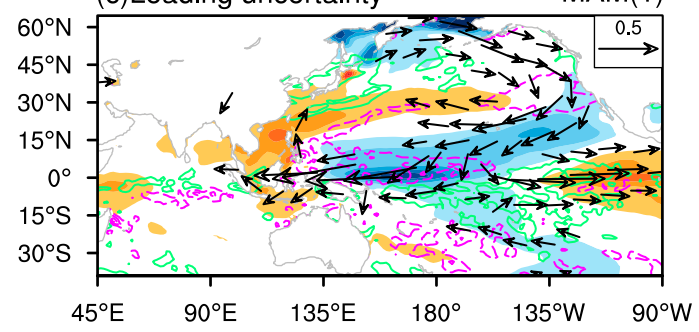

(b)Total approximate uncertainty $\mathrm{D}(0) \mathrm{JF}(1)$

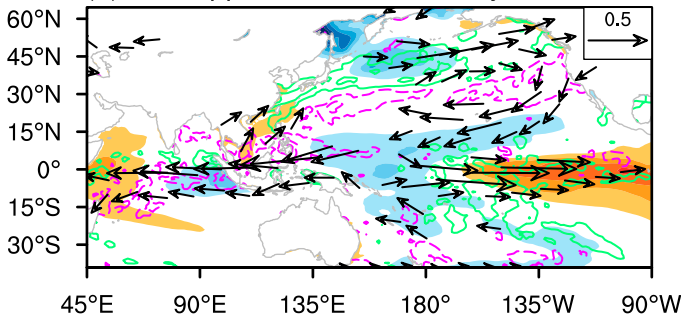

(d)Total approximate uncertainty $\operatorname{MAM}(1)$

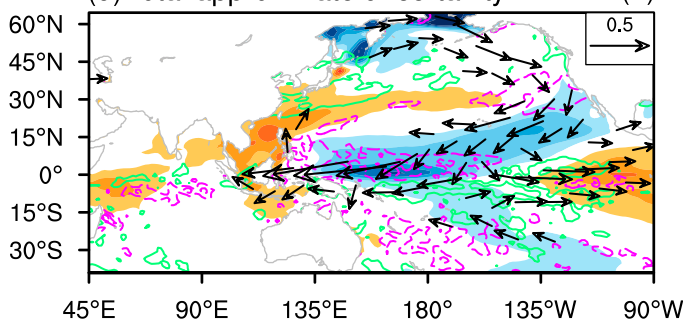

(f)Total approximate uncertainty JJA(1)

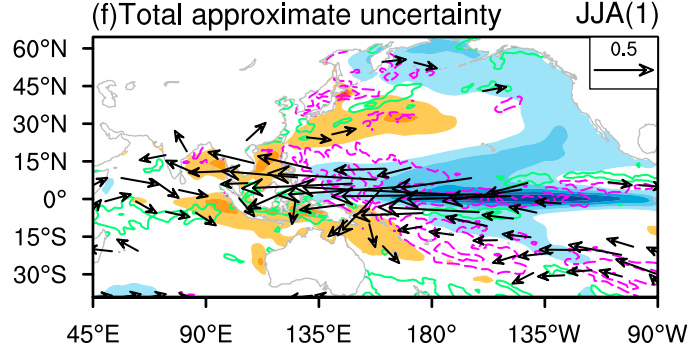

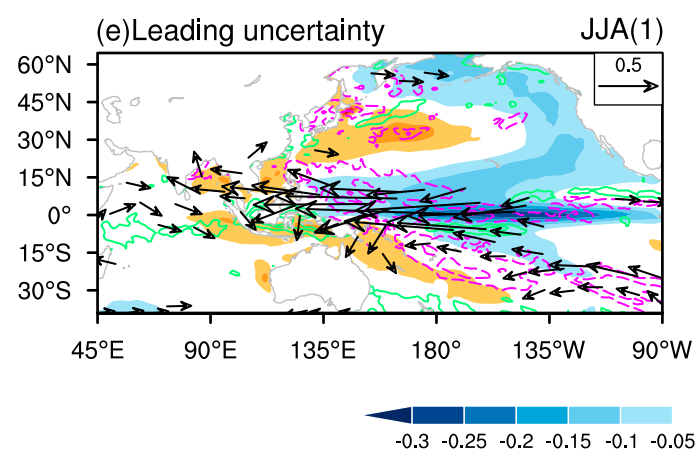

$\begin{array}{llllllllllll}-0.3 & -0.25 & -0.2 & -0.15 & -0.1 & -0.05 & 0.05 & 0.1 & 0.15 & 0.2 & 0.25 & 0.3\end{array}$

FIG. 6. Spatial distribution of decomposed uncertainty in $\delta$ SST (shading; units: K), $\delta U V 850$ (vectors; units: $\mathrm{m} \mathrm{s}^{-1}$ ), and $\delta$ precipitation (contours; units: $\mathrm{mm} \mathrm{day}^{-1}$ ): (left) leading uncertainty and (right) total approximate uncertainty. The green (purple) lines represent the positive (negative) precipitation anomalies. The contour ranges from -0.40 to $0.40 \mathrm{~mm} \mathrm{day}^{-1}$ with an interval of $0.15 \mathrm{~mm}$ day $^{-1}$. Wind magnitudes less than $0.2 \mathrm{~m} \mathrm{~s}^{-1}$ are omitted. 
(a)

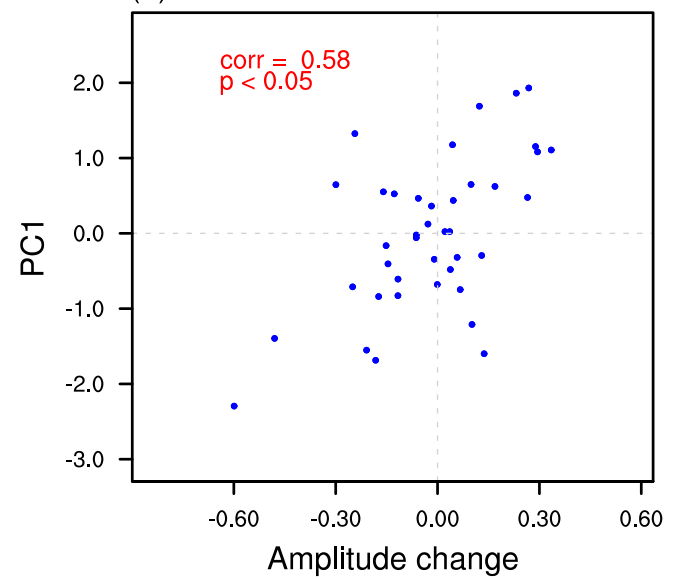

(c)

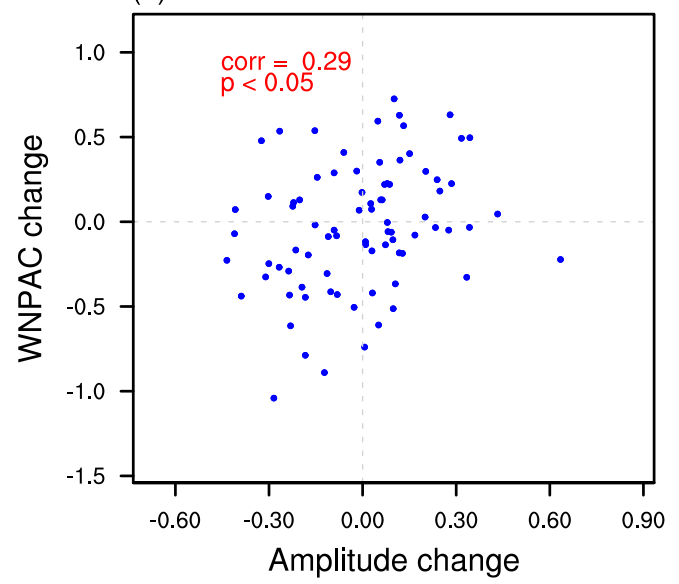

(b)

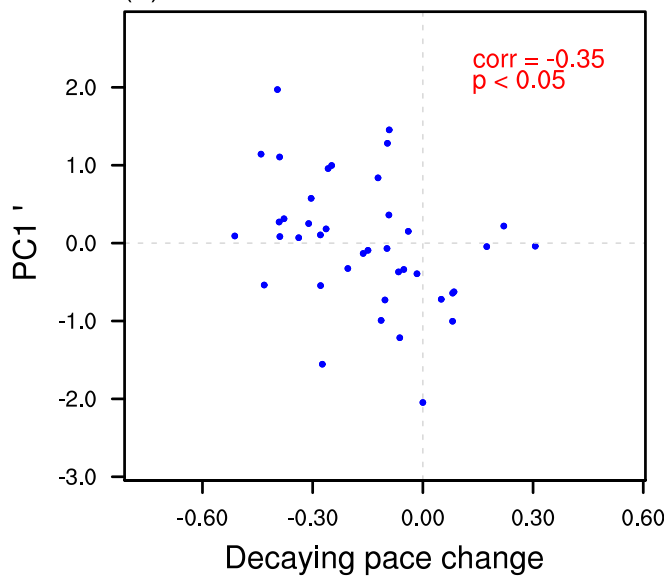

(d)

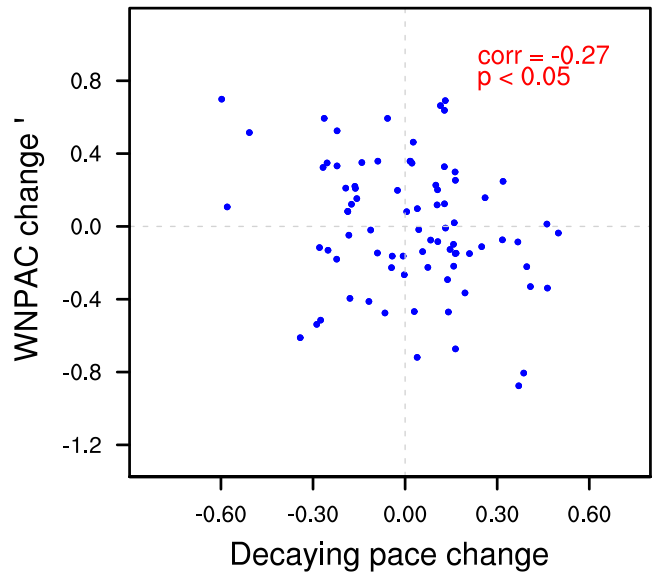

FIG. 7. Scatter diagram for (a) PC1 and El Niño amplitude change and (b) $\mathrm{PC}^{\prime}$ and El Niño decaying pace change. The correlation coefficients indicated at top of the panel are significant at the $95 \%$ confidence level using the Student's $t$ test. (c) The WNPAC index and El Niño amplitude change in the 1800-yr preindustrial control run. (d) The WNPAC index ${ }^{\prime}$ and El Niño decaying pace change in the 1800-yr preindustrial control run. The El Niño amplitude is defined as the deviation of the $\mathrm{D}(0) \mathrm{JF}(1)$ Niño-3.4 index, while the El Niño decaying pace is defined as the JJA(1) Niño-3.4 index minus the $\mathrm{D}(0) \mathrm{JF}(1)$ Niño-3.4 index. $\mathrm{PC}^{\prime}$ and WNPAC index ${ }^{\prime}$ indicate the remaining parts of PC1 and the WNPAC index after removing the linear influences of El Niño amplitude change, respectively. The correlation coefficients indicated at the top of the panel are significant at the $95 \%$ confidence level using the Monte Carlo nonparametric test.

wind anomalies from the east over the central and eastern subtropical Pacific induce negative SST anomalies in the subtropical Pacific by increasing the upward latent heat flux from the ocean (Fig. 8b). These anomalies then feedback to modify wind anomalies via convection. This intensified NPO-driven SST cooling can be maintained until summer via the windevaporation-SST (WES) feedback and expands to the tropical central Pacific through SFM (Vimont et al. 2001, 2003a) and generates the easterly wind anomalies in the equatorial Pacific, accelerates the demise of El Niño, thus strengthening the summertime WNPAC (Figs. 8d,f). Thus, the members that project stronger (weaker) positive SLP anomalies over the North Pacific tend to produce cooler (warmer) SST anomalies over the tropical central Pacific and stronger (weaker) easterly wind anomalies over the tropical western Pacific during the following spring. These anomalies sustain into summer and accelerate (prolong) the demise of El Niño, strengthening (weakening) the summertime WNPAC. Note that the decomposed uncertainty of changes in SST anomalies in Fig. 8a is smaller than that in Fig. 8b by about one order of magnitude, which indicates the major role of the nonamplitude change uncertainty.

\section{Summary and discussion}

It is important to understand how the relationship between El Niño and the western Pacific climate will change as a result of global warming. Here, we show evidence that the uncertainty in the WNPAC projection mainly arises from internal El Niño variabilities based on a 40 -member large ensemble from the CESM-LE project. We separate the contributions of El Niño amplitude and nonamplitude changes to the leading 
Amplitude Change Uncertainty
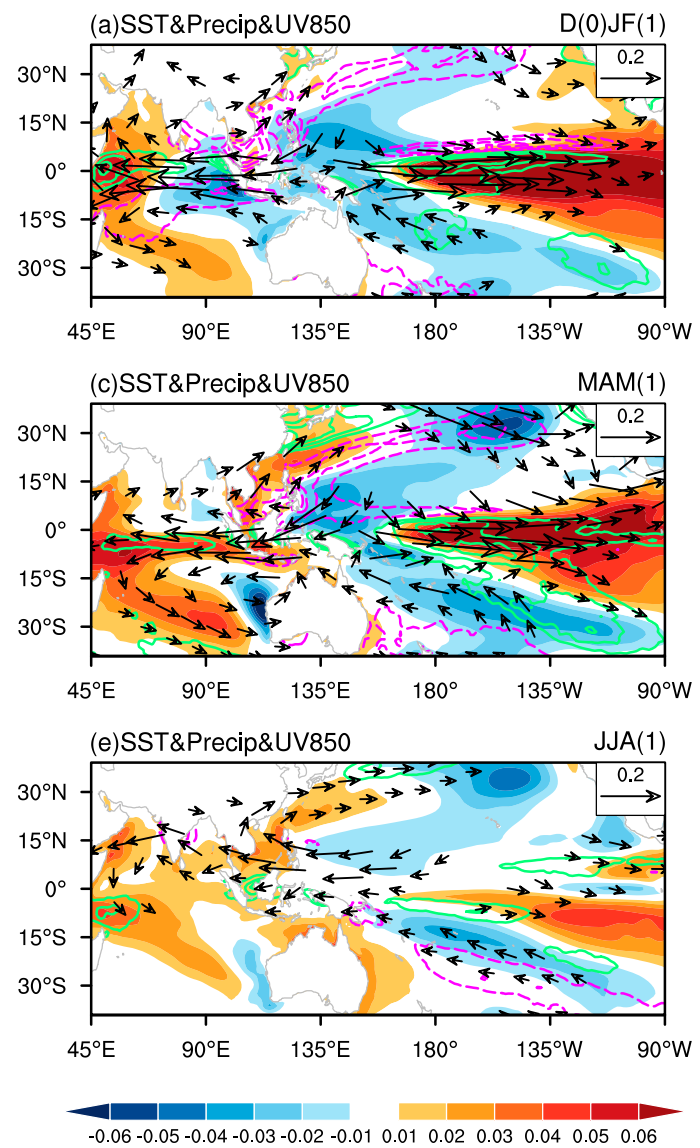

Non-amplitude Change Uncertainty
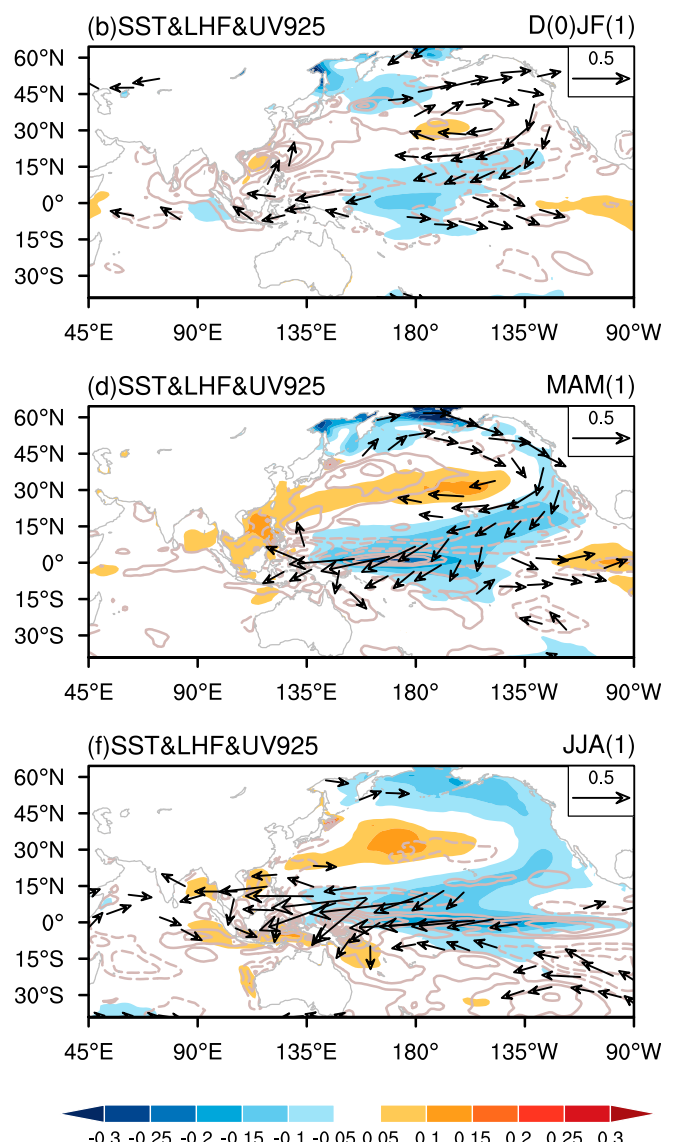

FIG. 8. Spatial distribution of amplitude change uncertainty for $\delta S S T$ (shading; units: K), $\delta$ UV850 (vectors; units: $\mathrm{m} \mathrm{s}^{-1}$ ), and $\delta$ precipitation (contours; units: $\mathrm{mm} \mathrm{day}^{-1}$ ) in (a) $\mathrm{D}(0) \mathrm{JF}(1)$, (c) MAM(1), and (e) JJA(1). The green (purple) lines represent the positive (negative) precipitation anomalies. The contours range from -0.1 to $0.1 \mathrm{~mm} \mathrm{day}^{-1}$ with an interval of $0.025 \mathrm{~mm} \mathrm{day}^{-1}$. Wind magnitudes of less than $0.05 \mathrm{~m} \mathrm{~s}^{-1}$ are omitted. (b) Spatial distribution of nonamplitude change uncertainty for $\delta \mathrm{SST}$ (shading; units: K), $\delta \mathrm{UV} 925$ (vectors; units: $\mathrm{m} \mathrm{s}^{-1}$ ), and Slatent heat flux (contours; units: $\mathrm{W} \mathrm{m}^{-2}$ ) in $\mathrm{D}(0) \mathrm{JF}(1)$. (d),(f) As in (b), but for MAM(1) and JJA(1), respectively. The solid (dashed) gray lines represent the positive (negative) latent heat flux anomalies. The contours range from -6.0 to $6.0 \mathrm{~W} \mathrm{~m}^{-2}$ with an interval of $1.0 \mathrm{~W} \mathrm{~m}^{-2}$ and the positive values indicate increasing heat flux into the ocean. Wind magnitudes less than $0.2 \mathrm{~m} \mathrm{~s}^{-1}$ are omitted.

uncertainty using a newly established decomposition method. The results show that the large intermember diversity mainly derives from the amplitude change uncertainty, related to the El Niño amplitude change, and nonamplitude change uncertainties, which reflect changes in the El Niño decaying pace. Our analyses can help resolve the controversies over changes in the ENSO-WNPAC relationship and highlight the importance of ENSO projection to the future change of western Pacific climate variability. The key processes are shown in Fig. 9 and the major findings are summarized as follows:

1) Unlike most CMIP5 models, CESM-LE can reproduce the seasonal evolution of the El Niño-WNPAC teleconnection. However, a considerable intermember diversity in WNPAC response to global warming exists in CESM-LE, indicating the dominant role of internal variability in modulating the El Niño-WNPAC relationship.
2) Based on regression analysis, a new decomposition method is developed to separate the contributions of El Niño amplitude change and nonamplitude change to the leading uncertainty in WNPAC projection. Results of the decomposition analysis indicate that about $23 \%$ of the uncertainty originates from El Niño amplitude change while $77 \%$ of the uncertainty arises from changes in WNPAC response to El Niño-related SST anomalies.

3) Decomposed spatial distributions of SST and circulation anomalies suggest that changes in El Niño-induced SST anomalies in the equatorial eastern Pacific and changes in El Niño decaying pace with TCP cooling are essential to WNPAC change, which is further confirmed by the 1800-yr preindustrial run. El Niño amplitude affects the WNPAC through influencing the TIO capacitor effect, whereas the El Niño decaying pace does so through influencing the 


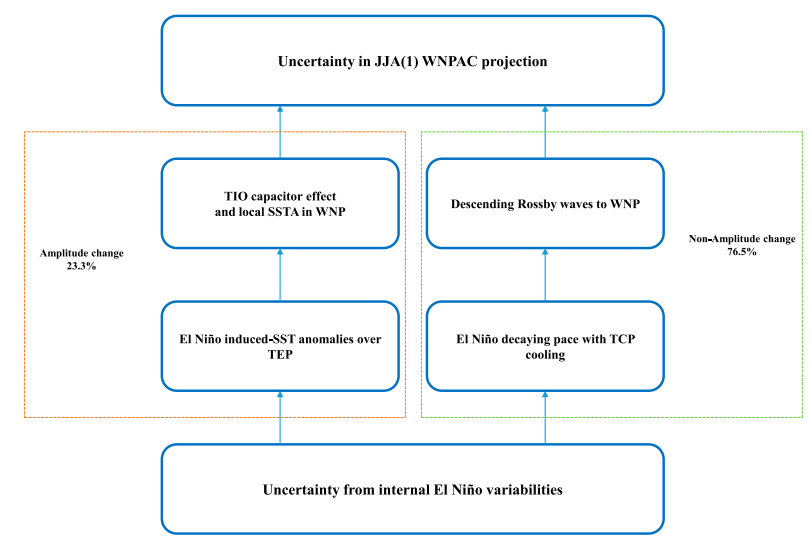

FIG. 9. Schematic diagram illustrating the mechanism underlying different sources of uncertainty in the WNPAC projection derived from CESM-LE. The numbers indicate the relative ratios of area-averaged amplitude change uncertainty and nonamplitude change uncertainty to the total approximate uncertainty as labeled in Fig. 4.

strength of the descending Rossby waves to WNP regions. Moreover, changes in the El Niño decaying pace with TCP cooling are modulated by midlatitude processes.

Previous studies have demonstrated the impact of El Niño amplitude change, but the effects of other internal El Niño properties, such as period, flavors, asymmetry, and teleconnection, have received little attention. Our decomposition methods can be used to diagnose the origin of uncertainty related to El Niño in climate projections and the relevant mechanisms. In addition to amplitude change, we address the role of the El Niño decaying pace in modulating the El Niño-East Asian climate connection affected by global warming, which suggests that a better understanding of the El Niño amplitude and El Niño decaying pace could help reduce the uncertainty in the WNPAC projection.

To facilitate the discussion, here we only showed the positive phase of the regression (i.e., the El Niño condition) for brevity, because the response of WNPAC to El Niño is usually stronger than that to La Niña (Wu et al. 2010b). We also analyzed the results of the La Niña condition (figures not shown). The first intermember EOF mode explains $22.2 \%$ of the total variance in La Niña condition, displaying a reverse spatial distribution to that in El Niño condition (Fig. 3a). The intermember correlation coefficient between changes in the WNPAC index and PC1 is -0.79 , slightly lower than that in El Niño condition (0.92, Fig. 3c). The decomposition results also suggest that the uncertainty of La Niña-related WNPAC changes are mainly from the nonamplitude change uncertainty, which is consistent with the El Niño condition (Fig. 4). The above results suggest that the decomposition method and conclusions are applicable to both phases of ENSO, though some asymmetries exist.

The present study is based on the large ensemble simulations from the CESM model. To investigate the robustness of the conclusions, we also compared the results derived from the CESM-LE with another 50-member ensemble of CanESM2 (figures not shown). The first EOF mode of $\delta \zeta_{850}$ in CanESM2 explains $43.4 \%$ of the total variance, characterized by a meridional dipole pattern over the WNP region. Compared with CESM-LE, the negative center in CanESM2 shifts slightly northward over the WNP, which is due to the model bias in CanESM2 in the simulation of ENSO decaying pace (Jiang et al. 2017). We then apply the decomposition method to separate the contributions of El Niño amplitude change from the leading uncertainty in CanESM2. We find that while the results are qualitatively consistent, the quantitative contributions of the decomposed terms are a bit model dependent. Most of the uncertainty in the El Niño-related WNPAC projection is still attributed to the nonamplitude change, but accounting for approximately $90 \%$, higher than that in CESMLE. Another notable difference is that the remaining part of the uncertainty mainly arises from historical nonamplitude change in CanESM2, while it arises from El Niño amplitude change in CESM-LE. Despite these quantitative differences, the availability of the decomposition method and the major role of the nonamplitude uncertainty are qualitatively consistent between two models. The results from CanESM2 here also confirm the recent conclusions by Chen and $\mathrm{Yu}$ (2020) to some extent that the NPO-ENSO relationship is modulated by internal climate variability.

In this study, we mainly focus on the role of ENSO-related uncertainty in the WNPAC projection; however, other factors unrelated to ENSO such as internal atmospheric variability and SST variations from other regions might also contribute. For example, with the absence of ENSO, the WNPAC is associated with the variation of the meridional temperature gradient in the upper troposphere (Chou et al. 2003). The Indian Ocean could induce a cross-equatorial quadrupole rainfall pattern linking up with the WNP summer climate without the influence of ENSO (Crétat et al. 2016). The El Niño-WNPAC relationship can be modulated by different phases of the PDO (Song and Zhou 2015). Whether and how ENSO-unrelated uncertainty takes effect deserves further study.

Acknowledgments. MW and TZ are supported by National Natural Science Foundation of China under Grant 41988101. $\mathrm{XC}$ is supported by National Key R\&D Program of China under Grant 2020YFA0608904 and National Natural Science Foundation of China under Grant 41605057.

Data availability statement. The observational atmospheric variables and surface temperature datasets are available on the Climate Data Guide website (https://climatedataguide.ucar.edu). The CESM-LE project data can be obtained from http:// www.cesm.ucar.edu/projects/community-projects/LENS/datasets.html. The CMIP5 data are available from the following website: https://esgf-node.llnl.gov/search/cmip5/.

\section{REFERENCES}

Chang, C.-P., Y. Zhang, and T. Li, 2000: Interannual and interdecadal variations of the East Asian summer monsoon and tropical Pacific SSTs. Part I: Roles of the subtropical ridge. J. Climate, 13, 4310-4325, https://doi.org/10.1175/ 1520-0442(2000)013<4310:IAIVOT>2.0.CO;2. 
Chen, S., and B. Yu, 2020: The seasonal footprinting mechanism in large ensemble simulations of the second generation Canadian Earth System Model: Uncertainty due to internal climate variability. Climate Dyn., 55, 2523-2541, https://doi.org/ 10.1007/s00382-020-05396-y.

Chen, W., J.-K. Park, B. Dong, R. Lu, and W.-S. Jung, 2012: The relationship between El Niño and the western North Pacific summer climate in a coupled GCM: Role of the transition of El Niño decaying phases. J. Geophys. Res., 117, D12 111, https://doi.org/10.1029/2011JD017385.

_ of the western North Pacific anticyclone response to the short decaying El Niño event due to greenhouse warming. J. Climate, 29, 3607-3627, https://doi.org/10.1175/JCLI-D-15-0195.1.

Chen, X., and T. Zhou, 2014: Relative role of tropical SST forcing in the 1990s periodicity change of the Pacific-Japan pattern interannual variability. J. Geophys. Res., 119, 13 043-13 066, https://doi.org/10.1002/2014JD022064.

Chou, C., J.-Y. Tu, and J.-Y. Yu, 2003: Interannual variability of the western North Pacific summer monsoon: Differences between ENSO and non-ENSO years. J. Climate, 16, 2275-2287, https://doi.org/10.1175/2761.1.

Chowdary, J., S. Xie, H. Tokinaga, Y. Okumura, H. Kubota, N. Johnson, and X. Zheng, 2012: Inter-decadal variations in ENSO teleconnection to the Indo-western Pacific for 1870-2007. J. Climate, 25, 1722-1744, https://doi.org/10.1175/JCLI-D-11-00070.1.

Compo, G. P., and Coauthors, 2011: The Twentieth Century Reanalysis Project. Quart. J. Roy. Meteor. Soc., 137, 1-28, https://doi.org/10.1002/qj.776.

Crétat, J., P. Terray, S. Masson, K. P. Sooraj, and M. K. Roxy, 2016: Indian Ocean and Indian summer monsoon: Relationships without ENSO in ocean-atmosphere coupled simulations. Climate Dyn., 49, 1429-1448, https://doi.org/10.1007/s00382-016-3387-x.

Deser, C., A. Phillips, V. Bourdette, and H. Teng, 2010: Uncertainty in climate change projections: The role of internal variability. Climate Dyn., 38, 527-546, https://doi.org/10.1007/s00382010-0977-x.

— I. R. Simpson, A. S. Phillips, and K. A. McKinnon, 2018: How well do we know ENSO's climate impacts over North America, and how do we evaluate models accordingly? J. Climate, 31, 4991-5014, https://doi.org/10.1175/JCLI-D-17-0783.1.

Feng, J., L. Wang, and W. Chen, 2013: How does the East Asian summer monsoon behave in the decaying phase of El Niño during different PDO phases? J. Climate, 27, 2682-2698, https://doi.org/10.1175/JCLI-D-13-00015.1.

Hawkins, E., and R. Sutton, 2009: The potential to narrow uncertainty in regional climate predictions. Bull. Amer. Meteor. Soc., 90, 1095-1108, https://doi.org/10.1175/2009BAMS2607.1.

He, C., and T. Zhou, 2014: Decadal change of the connection between summer western North Pacific subtropical high and tropical SST in the early 1990s. Atmos. Sci. Lett., 16, 253-259, https://doi.org/10.1002/asl2.550.

,-- , and T. Li, 2019: Weakened anomalous western North Pacific anticyclone during an El Niño-decaying summer under a warmer climate: Dominant role of the weakened impact of the tropical Indian Ocean on the atmosphere. J. Climate, 32, 213230, https://doi.org/10.1175/JCLI-D-18-0033.1.

He, J., and Z. Zhu, 2015: The relation of South China Sea monsoon onset with the subsequent rainfall over the subtropical East Asia. Int. J. Climatol., 35, 4547-4556, https://doi.org/10.1002/ joc. 4305 .

Hu, K., G. Huang, X.-T. Zheng, S.-P. Xie, X. Qu, Y. Du, and L. Liu, 2014: Interdecadal variations in ENSO influences on northwest
Pacific-East Asian early summertime climate simulated in CMIP5 models. J. Climate, 27, 5982-5998, https://doi.org/ 10.1175/JCLI-D-13-00268.1.

Huang, B., and Coauthors, 2016: Further exploring and quantifying uncertainties for extended reconstructed sea surface temperature (ERSST) version 4 (v4). J. Climate, 29, 3119-3142, https://doi.org/10.1175/JCLI-D-15-0430.1.

Huang, G., K. M. Hu, and S.-P. Xie, 2010: Strengthening of tropical Indian Ocean teleconnection to the northwest Pacific since the mid-1970s: An atmospheric GCM study. J. Climate, 23, 52945304, https://doi.org/10.1175/2010JCLI3577.1.

Hurrell, J. W., and Coauthors, 2013: The Community Earth System Model: A framework for collaborative research. Bull. Amer. Meteor. Soc., 94, 1339-1360, https://doi.org/10.1175/BAMS-D12-00121.1.

Jiang, W., G. Huang, K. Hu, R. Wu, H. Gong, X. Chen, and W. Tao, 2017: Diverse relationship between ENSO and the northwest Pacific summer climate among CMIP5 models: Dependence on the ENSO decay pace. J. Climate, 30, 109-127, https:// doi.org/10.1175/JCLI-D-16-0365.1.

,$- \ldots$, P. Huang, and K. Hu, 2018: Weakening of northwest Pacific anticyclone anomalies during post-El Niño summers under global warming. J. Climate, 31, 3539-3555, https:// doi.org/10.1175/JCLI-D-17-0613.1.

$-,-,-, \mathrm{R} . \mathrm{Wu}, \mathrm{K} . \mathrm{Hu}$, and W. Chen, 2019: Northwest Pacific anticyclonic anomalies during post-El Niño summers determined by the pace of El Niño decay. J. Climate, 32, 34873503, https://doi.org/10.1175/JCLI-D-18-0793.1.

Kay, J. E., and Coauthors, 2015: The Community Earth System Model (CESM) large ensemble project: A community resource for studying climate change in the presence of internal climate variability. Bull. Amer. Meteor. Soc., 96, 1333-1349, https://doi.org/10.1175/BAMS-D-13-00255.1.

Kirchmeier-Young, M. C., F. W. Zwiers, and N. P. Gillett, 2017: Attribution of extreme events in Arctic sea ice extent. J. Climate, 30, 553-571, https://doi.org/10.1175/JCLI-D-16-0412.1.

Li, S., J. Lu, G. Huang, and K. Hu, 2008: Tropical Indian Ocean basin warming and East Asian summer monsoon: A multiple AGCM study. J. Climate, 21, 6080-6088, https://doi.org/ 10.1175/2008JCLI2433.1.

Li, T., B. Wang, B. Wu, T. Zhou, C.-P. Chang, and R. Zhang, 2017: Theories on formation of an anomalous anticyclone in western North Pacific during El Niño: A review. J. Meteor. Res., 31, 987-1006, https://doi.org/10.1007/s13351-017-7147-6.

Maher, N., D. Matei, S. Milinski, and J. Marotzke, 2018: ENSO change in climate projections: Forced response or internal variability? Geophys. Res. Lett., 45, 11,390-11,398, https:// doi.org/10.1029/2018GL079764.

Park, J.-Y., S.-W. Yeh, J.-S. Kug, and J. Yoon, 2012: Favorable connections between seasonal footprinting mechanism and $\mathrm{El}$ Niño. Climate Dyn., 40, 1169-1181, https://doi.org/10.1007/ s00382-012-1477-y.

Song, F., and T. Zhou, 2015: The crucial role of internal variability in modulating the decadal variation of the East Asian summer monsoon-ENSO relationship during the twentieth century. J. Climate, 28, 7093-7107, https://doi.org/10.1175/JCLI-D-1400783.1.

Vimont, D. J., D. S. Battisti, and A. C. Hirst, 2001: Footprinting: A seasonal connection between the tropics and mid-latitudes. Geophys. Res. Lett., 28, 3923-3926, https://doi.org/10.1029/ 2001 GL013435.

$\ldots, \ldots$, and — $\_$2003a: The seasonal footprinting mechanism in the CSIRO general circulation models. J. Climate, 
16, 2653-2667, https://doi.org/10.1175/1520-0442(2003)016<2653: TSFMIT>2.0.CO;2.

_- J. M. Wallace, and D. S. Battisti, 2003b: The seasonal footprinting mechanism in the Pacific: Implications for ENSO. J. Climate, 16, 2668-2675, https://doi.org/10.1175/ 1520-0442(2003)016<2668:TSFMIT>2.0.CO;2.

Wang, B., and Q. Zhang, 2002: Pacific-East Asian teleconnection. Part II: How the Philippine Sea anomalous anticyclone is established during El Niño development. J. Climate, 15, 3252-3265, https://doi.org/10.1175/1520-0442(2002)015<3252: PEATPI $>2.0 . \mathrm{CO} ; 2$.

$\longrightarrow$, R. Wu, and J. X. Fu, 2000: Pacific-East Asian teleconnection: How does ENSO affect East Asian climate? J. Climate, 13, 1517-1536, https://doi.org/10.1175/1520-0442(2000)013<1517: PEATHD $>2.0 . \mathrm{CO} ; 2$.

,$- \ldots$, and T. Li, 2003: Atmosphere-warm ocean interaction and its impacts on Asian-Australian monsoon variability. J. Climate, 16, 1195-1211, https://doi.org/10.1175/1520-0442(2003) $16<1195$ :AOIAII $>2.0$. CO; 2 .

_- J. Yang, T. Zhou, and B. Wang, 2008: Interdecadal changes in the major modes of Asian-Australian monsoon variability: Strengthening relationship with ENSO since the late 1970s. J. Climate, 21, 1771-1789, https://doi.org/10.1175/2007JCLI1981.1.

__ B. Xiang, and J.-Y. Lee, 2013: Subtropical high predictability establishes a promising way for monsoon and tropical storm predictions. Proc. Natl. Acad. Sci. USA, 110, 2718-2722, https://doi.org/10.1073/pnas.1214626110.

Wu, B., T. Li, and T. Zhou, 2010a: Relative contributions of the Indian Ocean and local SST anomalies to the maintenance of the western North Pacific anomalous anticyclone during the El Niño decaying summer. J. Climate, 23, 2974-2986, https:// doi.org/10.1175/2010JCLI3300.1.

_ - , and —_, 2010b: Asymmetry of atmospheric circulation anomalies over the western North Pacific between El Niño and La Niña. J. Climate, 23, 4807-4822, https://doi.org/10.1175/ 2010JCLI3222.1.

—_, T. Zhou, and T. Li, 2017: Atmospheric dynamic and thermodynamic processes driving the western North Pacific anomalous anticyclone during El Niño. Part I: Maintenance mechanisms. J. Climate, 30, 9621-9635, https://doi.org/ 10.1175/JCLI-D-16-0489.1.

Wu, M., T. Zhou, X. Chen, and B. Wu, 2020: Intermodel uncertainty in the projection of the anomalous western North
Pacific anticyclone associated with El Niño under global warming. Geophys. Res. Lett., 47, e2019GL086 139, https:// doi.org/10.1029/2019GL086139.

Wu, R., and B. Wang, 2002: A contrast of the East Asian summer monsoon-ENSO relationship between 1962-77 and 1978-93. J. Climate, 15, 3266-3279, https://doi.org/10.1175/ 1520-0442(2002)015<3266:ACOTEA > 2.0.CO;2.

Xiang, B., B. Wang, W. Yu, and S. Xu, 2013: How can anomalous western North Pacific subtropical high intensify in late summer? Geophys. Res. Lett., 40, 2349-2354, https://doi.org/ 10.1002/grl.50431.

Xie, M., and C. Wang, 2020: Decadal variability of the anticyclone in the western North Pacific. J. Climate, 33, 9031-9043, https:// doi.org/10.1175/JCLI-D-20-0008.1.

Xie, S.-P., K. Hu, J. Hafner, H. Tokinaga, Y. Du, G. Huang, and T. Sampe, 2009: Indian Ocean capacitor effect on indo-western Pacific climate during the summer following El Niño. J. Climate, 22, 730-747, https://doi.org/10.1175/ 2008JCLI2544.1.

—, Y. Du, G. Huang, X.-T. Zheng, H. Tokinaga, K. Hu, and Q. Liu, 2010: Decadal shift in El Niño influences on Indowestern Pacific and East Asian climate in the 1970s. J. Climate, 23, 3352-3368, https://doi.org/10.1175/2010JCLI3429.1.

Zhang, R., Q. Min, and J. Su, 2017: Impact of El Niño on atmospheric circulations over East Asia and rainfall in China: Role of the anomalous western North Pacific anticyclone. Sci. China Earth Sci., 60, 1124-1132, https://doi.org/10.1007/s11430-016-9026-x.

Zheng, X.-T., S.-P. Xie, and Q. Liu, 2011: Response of the Indian Ocean basin mode and its capacitor effect to global warming. J. Climate, 24, 6146-6164, https://doi.org/10.1175/ 2011JCLI4169.1.

, L.-H. Lv, and Z.-Q. Zhou, 2016: Intermodel uncertainty in ENSO amplitude change tied to Pacific Ocean warming pattern. J. Climate, 29, 7265-7279, https://doi.org/10.1175/ JCLI-D-16-0039.1.

— C. Hui, and S.-W. Yeh, 2017: Response of ENSO amplitude to global warming in CESM large ensemble: Uncertainty due to internal variability. Climate Dyn., 50, 4019-4035, https:// doi.org/10.1007/s00382-017-3859-7.

Zhou, X., F. Liu, B. Wang, B. Xiang, C. Xing, and H. Wang, 2019: Different responses of East Asian summer rainfall to El Niño decays. Climate Dyn., 53, 1497-1515, https://doi.org/10.1007/ s00382-019-04684-6. 